\title{
New Emerging Infectious Disease; Enterovirus D68, MERS, Ebola, What is its Hematological Appearance?
}

\author{
Viroj Wiwanitkit*
}

Department of Medicine, Hainan Medical University, Thailand

*Corresponding author: Wiwanitkit, V. Department of Medicine, Hainan Medical University, Thailand 10160. Email: wviroj@ yahoo.com

Received Date: November 13, 2015 Accepted Date: November 15, 2015 Published Date: November 16, 2015

Citation: Wiwanitkit, V. New Emerging Infectious Disease; Enterovirus D68, MERS, Ebola, What is its Hematological Appearance? (2016) Int J Hematol Therap 2(1): 1

In the present day, emerging infectious disease is usually the new global public health threaten. There are several new emerging infections. For hematologist, the interesting concern is on the hematological presentation of those new infections. However, as a new disease, limited knowledge on the hematological appearance is usually seen. For example, enterovirus D68 is the new emerging infection that causes severe respiratory and neurological diseases. Its epidemic in USA becomes big public health issue ${ }^{[1]}$. There is still no specific study in the hematological appearance. For MERS, there are some reports on its hematological problem. There is a note that white blood cell count is low, the proportion of the neutrophils is high and that of the platelet is low ${ }^{[2]}$. For Ebola, there are also some reports on its hematological problem. Since it is an older found infection comparing to the previous two other disease, more evidences can be seen. The animal model study on hematology aspect was also reported ${ }^{[3]}$. In human case, "thrombocytopenia, lymphopenia, and neutrophilia" is common ${ }^{[4]}$. As noted, the research on the hematological aspect of new emerging disease should be focused. Since the hematological test is the basic test in clinical practice, the data on this aspect will be useful for diagnosis and screening of disease.

\section{References}

1. Principi, N., Esposito, S. Enterovirus D-68: an emerging cause of infection. (2015) Expert Rev Respir Med 4: 1-9.

2. Ling, Y., Qu, R., Luo, Y. Clinical analysis of the first patient with imported Middle East respiratorysyndrome in China. Zhonghua Wei Zhong Bing Ji Jiu Yi Xue 27(8): 630-634.

3. Dadaeva, A.A., Sizikova, L.P., Subbotina, E.L., et al. Hematological and immunological parameters during Ebola virus passages in guinea-pigs. (2006) Vopr Virusol 51(4): 32-37.

4. Formenty, P., Hatz, C., Le Guenno, B., et al. Human infection due to Ebola virus, subtype Côte d'Ivoire: clinical and biologic presentation. (1999) J Infect Dis 179 Suppl 1: S48-53. 